\title{
Petri Net Model for Serious Games Based on Motivation Behavior Classification
}

\author{
Moh. Aries Syufagi, ${ }^{1,2}$ Mochamad Hariadi, ${ }^{3}$ and Mauridhi Hery Purnomo ${ }^{3}$ \\ ${ }^{1}$ Multimedia Studies Program, Public Vocational High School 1, Jl. Tongkol No. 03, Jawa Timur, Bangil 67153, Indonesia \\ ${ }^{2}$ Department of Information, STMIK Yadika, Jl. Bader No. 7, Kalirejo, Jawa Timur, Bangil 67153, Indonesia \\ ${ }^{3}$ Electrical Department, Faculty of Industrial Technology, Institut Teknologi Sepuluh Nopember, Kampus ITS Keputih, Sukolilo, \\ Jawa Timur, Surabaya 60111, Indonesia
}

Correspondence should be addressed to Moh. Aries Syufagi; moh.aries.syufagi@gmail.com

Received 29 November 2012; Accepted 30 January 2013

Academic Editor: Hanqiu Sun

Copyright (C) 2013 Moh. Aries Syufagi et al. This is an open access article distributed under the Creative Commons Attribution License, which permits unrestricted use, distribution, and reproduction in any medium, provided the original work is properly cited.

Petri nets are graphical and mathematical tool for modeling, analyzing, and designing discrete event applicable to many systems. They can be applied to game design too, especially to design serous game. This paper describes an alternative approach to the modeling of serious game systems and classification of motivation behavior with Petri nets. To assess the motivation level of player ability, this research aims at Motivation Behavior Game (MBG). MBG improves this motivation concept to monitor how players interact with the game. This modeling employs Learning Vector Quantization (LVQ) for optimizing the motivation behavior input classification of the player. MBG may provide information when a player needs help or when he wants a formidable challenge. The game will provide the appropriate tasks according to players' ability. MBG will help balance the emotions of players, so players do not get bored and frustrated. Players have a high interest to finish the game if the players are emotionally stable. Interest of the players strongly supports the procedural learning in a serious game.

\section{Introduction}

Nowadays, serious games and game technology are poised to transform the way of educating and training students at all levels. From the previous research about serious game, it is known that serious game supports the education process. Marsh et al. [1] and Clark [2] state that serious game is learning through games which contain pedagogical aspects and is a part of e-learning tools/media [3-5]. Clark [2], Arnseth [6], and Smith [7] further state that learning method using game is better than the conventional one, since animations of learning material in game activate students' long-term memories.

On the other hand, game learning has an inverse relationship with learning test in many instances. Clark [8] gives details; pedagogy in games is often based on unguided discovery such as; minimal guidance for high skill works, overwhelming discovery evidence without any assistance for beginners/novice learners $[9,10]$, discovery technique design, and some game cause memory overwork and decrease the learning process [11].
Overload will not occur if the level of players' motivation behavior is controlled. Inal and Cagiltay [12] explain the research of Csikszentmihalyi and emphasized the balance between an individual's skills and difficulties of tasks. He theorizes that the occurrence of flow experiences depends on this balance and that if the balance does not exist between the individual's skills and the task, flow experiences cannot occur. Heavier duty resulted in faster frustration; the challenges are too easy, getting bored quickly.

Proper classification of motivation behavior can be used to control the challenge of difficulty of the game. Providing an appropriate level of difficulty to the level of motivation behavior in a game scenario will balance the emotions of the players. The game cannot provide an appropriate difficulty level of task if the players' motivation behavior is unknown.

By contrast, Clark [8] in Evaluating the Learning and Motivation Effects of Serious Games explains that the tests of motivation are most often unreliable and invalid. Selfreported enjoyment does not aid learning, because there is an opportunity to manipulate data. 
In this research, the proposal of the Motivation Behavior Game (MBG) is to eliminate the data manipulation of motivation tests in serious games. MBG is a model of indirect measurement of motivation levels. MBG is a players' motivation characteristics measurement by observing the players' motivation behavior; in this case, the players/respondents are students. The value of motivation behavior can be taken from the indicators that appear when a game takes place.

MBG is Pedagogic Player Character (PPC) based on artificial intelligent agent, and it can forecast the motivation character of players. Learning Vector Quantization (LVQ) method is used in MBG that functions to classify the players' motivation level. The teachers' data are neuron vector used in learning or supervising data in LVQ method. That will identify three multiobjective classifications in MBG, namely, mental effort, persistence, and active choice, taken from the players demonstration through the game.

Petri net is a tool used in the study of systems. Petri net theory allows a system to be modeled by a Petri net, a mathematical representation of the system [13]. Petri Net diagrams can become easier to read and to understand. It has a simple notation, being composed of only circles, bars, or boxes and at most three types of arcs, compared to UML's multiple diagram types using some of them for designing game systems. Text descriptions are usually very short, and not all transitions/places need names [14].

Analysis of the Petri net then can, hopefully, reveal important information about the structure and dynamic behavior of the modeled system. This information can then be used to evaluate the modeled system and to suggest improvements or changes [13]. The Petri nets' ability to model system with concurrent operations and conflicts is well documented. This can be of great help for game designers trying to model realtime action and strategy games [14].

\section{Related Work}

2.1. Motivation Measurement in Games. It is almost universally accepted that there is a positive correlation between motivation and learning. Instructional designers must pay more attention to motivational constructs when designing instruction and games. Bernard and Cannon [15] investigate the use of an emoticon based instrument, supporting the investigation with a study involving undergraduate students. At the end of each class period, the students were asked to indicate their level of motivation before and after the decision-making process, but before disclosure of results. Students used a 5-item, emoticon anchored scale ranging from highly unmotivated to highly motivated. This study has already noted the possibility of bias measurement resulting from administering questions relating to both motivations at the beginning and at the end of the class period. Another possibility is that the use of emoticons was too simplistic for the purpose.

Educational virtual games and simulations (EVGS) are also noted as agents that may enhance user motivation and satisfaction and subsequently engage learners in being innovative and the frequency they play. Higher levels of success in EVGS are measured by the intrinsic motivational factors created by the activity [16]. Konetes [16] analyzes the applications of learning simulations and games through the lens of the intrinsic and extrinsic motivational factors associated with different academic EVGS use. Learning to better control and apply these motivational concepts could enhance the value of educational simulations and magnify their impact and effectiveness.

Derbali and Frasson [17] investigated players' motivation during a serious game. The assessment of motivation was made using questionnaire (after Keller's ARCS model) and electroencephalography (EEG). Thirty-three subjects voluntarily took part in the test. Each subject was placed in front of two computers: one for playing and the other for answering the questionnaires. The result shows that the EEG wave's patterns are correlates with the increase of motivation during certain parts of a serious game play.

The motivation research in the game [15-17] is an extrinsic motivational. Thus, the motivation measurement process is still done separately of the game.

2.2. LVQ Method in Serious Game. Many studies use LVQ method for data classification in the game. Syufagi et al. [18] are designing the motivation measurement in game pedagogics. This research focuses on single objective motivation, that is, the classification level of mental effort only.

A Cognitive Skill Classification Based on Multiobjective Optimization Using Learning Vector Quantization for Serious Games [19] is LVQ research method in classification and optimization in multiobjective cognitive skill players.

Harini [20] studies Comprehensive Learning Achievement Affectivity using the LVQ method in serious game. This study aim at LVQ architecture to classify effective and ineffective use of time in serious games.

Abramson and Wechsler [21] show that the distributed representation found in Learning Vector Quantization (LVQ) enables the reinforcement in learning methods to cope with a large decision search space, defined in terms of equivalence classes of input patterns like those found in the game of Go. In particular, this paper describes S[arsa]LVQ.

2.3. Petri Net in Games. Araújo and Roque [14] describes an alternative; an approach to the modeling of game systems and game flow with Petri nets. They provide a case study to show that Petri nets can be used with advantages over other modeling languages.

Clempner [13] introduces a new modeling paradigm for the shortest path games representation with Petri nets. In this sense, he changes the traditional cost function by a trajectorytracking function which is also an optimal cost-to-target function.

Brom et al. [22] present a technique for specifying plots of these scenarios, which underpins the story manager of Europe 2045. The technique is based on a modification of Petri nets. On a general level, this paper discusses the strengths and weaknesses of Petri nets implementation in virtual storytelling. 
TABLE 1: Place on Motivation Behavior Game Model.

\begin{tabular}{ll}
\hline Place & Interpretation \\
\hline P1 & Problems arise in the game \\
P2 & Identify players behavior \\
P3 & Classification of Motivation Behavior Players \\
P4 & Pattern of Motivation Behavior Players \\
P5 & Motivation leveling algorithm \\
P6 & $\begin{array}{l}\text { Responds to the players level of motivation behavior } \\
\text { as the reference to the selection of problem in game }\end{array}$ \\
\hline
\end{tabular}

TABLE 2: Some typical interpretations of transitions and places.

\begin{tabular}{lll}
\hline Input places & Transition & Output places \\
\hline Input places & Transition & Output places \\
Preconditions & Event & Postconditions \\
Input data & Computation step & Output data \\
Input signals & Signal processor & Output signal \\
Resources needed & Task or job & Resources released \\
Conditions & Clause in logic & Conclusion(s) \\
Buffers & Processor & Buffers \\
\hline
\end{tabular}

Table 3: Formal definition of a Petri net.

A Petri net is a 5 tuple, $\mathrm{PN}=\left(P, T, F, W, M_{0}\right)$ where

$P=\left\{p_{1}, p_{2}, \ldots, p_{m}\right\}$ is a finite set of places,

$T=\left\{t_{1}, t_{2}, \ldots, t_{n}\right\}$ is a finite set of transitions,

$F \subseteq(P \times T) \cup(T \times P)$ is a set of $\operatorname{arcs}$ (flow relation),

$W: F \rightarrow\{1,2,3, \ldots\}$ is weight function,

$M_{0}: P \rightarrow\{0,1,2,3, \ldots\}$ is the initial marking,

$P \cap T=\varnothing$ and $P \cup T \neq \varnothing$.

A Petri net structure $N=(P, T, F, W)$ without any specific initial marking is denoted by $N$.

A Petri net with the given initial marking is denoted by $\left(N, M_{0}\right)$.

\section{Design System and Method}

The design system of MBG is illustrated in a model of Motivation Behavior Game with Petri net, and modeling functions use the LVQ method.

3.1. Petri Net. Petri nets were created by German mathematician Carl Adam Petri for the purpose of describing chemical processes [14]. They are graphical and mathematical tool for modeling [23], analyzing, and designing discrete event [14] applicable to many systems. Petri nets can be applied to other areas of game design, not just plot description or story managing [14].

Graphically, Petri nets are described as a diagram with circles (places), bar or squares (transitions), and arrows (arcs) connecting them [14]. To implement the Petri net interpretation needs to label the place and transition [24].

In [23], Murata shows some typical interpretations of transitions and their input and output places shown in Table 2, and the formal definition of a Petri net is given in Table 3.

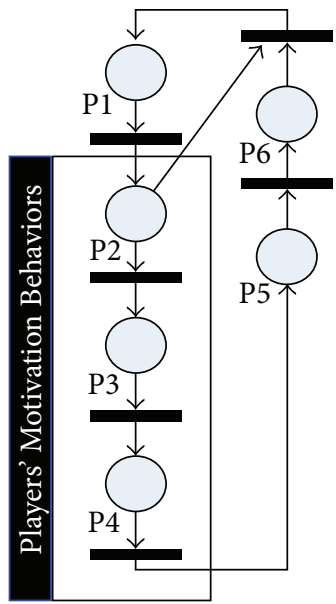

Figure 1: Model of Motivation Behavior Game with Petri net.

3.2. Model of Motivation Behavior Game with Petri Net. In addition to the development of motivation research in the game [15-17], there are also some researchers who use LVQ method for data classification in game [18-21]. MBG based on those two phenomena (motivation game and LVQ in game) are developed. Figure 1 shows the model of MBG with Petri net, whereas the interpretation of places on MBG model is shown in Table 1.

MBG is a game that measures the level of players' processbased motivation behavior; it gives more emphasis on the achievement level of interest, for example, calculating the number of leaving the problem, searching info, and using time to finish the job. The weakness of the measurementbased results is that it does not consider players' characteristics of the action in completing the mission in the game. Players' game characteristics are in the forms of motivation behavior in the process.

The result of the motivation behavior classification is used to level challenges of task in the game engine. The method of challenges leveling in game engine is using the algorithm which will adapt the motivation behavior classification. The accuracy of classification results will determine the accuracy of the game engine to provide the appropriate level of difficulty of the challenges in the task level generator. MBG supported achievement balance between an individual's motivation and difficulties of challenges. Moreover, it can prevent boredom and frustration.

The detail of MBG model with Petri net is shown in Figure 2, the interpretations detail of places on MBG model is shown in Table 4, and Table 5 shows the detail of transition.

For example $A$ is Cognitive Steps containing all skill contest with tests forms or all competitions items in the game (P1 in Table 4). The number of skill contest (test)/competition (game) is $A=\{t, b, o, c, m, i\} . t, b, o, c, m$, and $i$ are players' parameter in playing the game. $t$ is the number of how much time is used to finish the job (T208), $b$ is the number of correct answers in the tests or the number of victory in the game (T207), $o$ is the number of overlooking in tests or avoiding in games (T203), $m$ is the number of mistakes in the tests or the number of loses in the game (T205), $c$ is the number of 


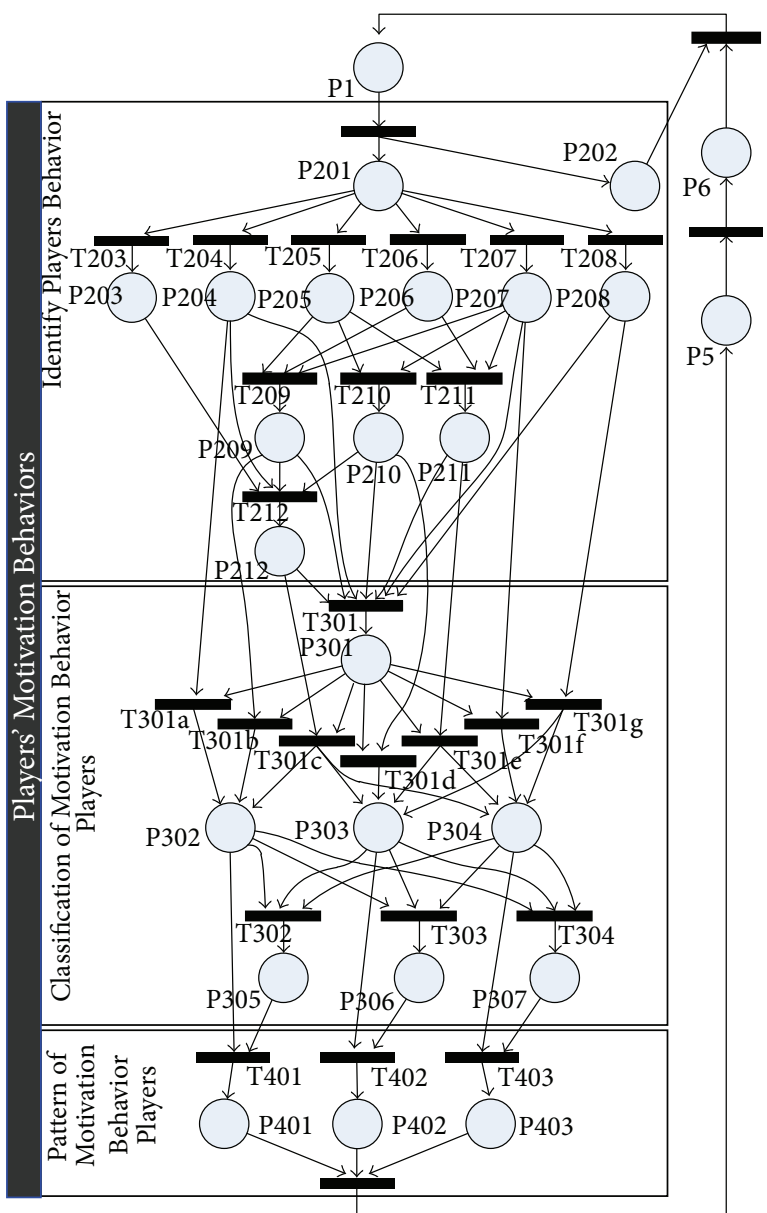

FIGURE 2: Details of Motivation Behavior Game Model.

hesitation (canceled) in the tests or stepping back (escaping) from competition in the game (T206), and $i$ is the number of how many times the players search info during the tests or to get help for the period of the game (T204).

$\operatorname{tr}=\{b, m\}$ is the condition when players try to answer a number of tests or try to finish all competition of MBG modeling which is also the indication of players' correct item/victory and mistakes/loses (P210 and T210):

$$
\operatorname{tr}=\frac{b+m}{2}
$$

$e=\{0.5 b, 0.3 m, 0.2 c\}$ is self-efficacy (P211 and T211) or ability, and also $q=\{b, m, c\}$ is the number of picking up questions from all of tests or playing all competition in the game (P209 and T209), that is, the content of players' characters in mistakes, correct items, and doubts in game:

$$
\begin{gathered}
e=0.5 b+0.3 m+0.2 c, \\
q=\frac{b+m+c}{3} .
\end{gathered}
$$

st is step report of player at some stage in the game. $q \in \mathrm{st}, \mathrm{tr} \epsilon$

\begin{tabular}{|c|c|}
\hline Place & Interpretation \\
\hline P1 & Problems arise in the game \\
\hline P201 & Players resolve the problem \\
\hline P202 & Players avoid/leave the problem \\
\hline P203 & $\begin{array}{l}\text { Number of how many times the players neglected } \\
\text { the tests or avoided the games }(o)\end{array}$ \\
\hline P204 & $\begin{array}{l}\text { Number of how many times the players search } \\
\text { info }(i)\end{array}$ \\
\hline P205 & Number of wrong in tests or losses in games $(m)$ \\
\hline P206 & $\begin{array}{l}\text { Number of the players is uncertainty/to decline } \\
\text { (escape) }(c)\end{array}$ \\
\hline P207 & Number of True in games or win in games $(b)$ \\
\hline P208 & $\begin{array}{l}\text { Number of how much the players use time to } \\
\text { finish the job }(t)\end{array}$ \\
\hline P209 & $\begin{array}{l}\text { Fixes the value of pick question/playing the game } \\
(q)\end{array}$ \\
\hline P210 & Fixes the value of trying to answer/to finish (tr) \\
\hline P211 & Fixes the value of self-efficacy/Ability $(e)$ \\
\hline P212 & Step report of player at some stage (st) \\
\hline P301 & Fixes the value of maximal ( $\max )$ \\
\hline P302 & $\begin{array}{l}\text { LVQ method to classify the players motivation } \\
\text { behavior of active choice (ac) into; low active } \\
\text { choice }\left(\mathrm{ac}_{1}\right) \text {, semi-active choice }\left(\mathrm{ac}_{2}\right) \text {, or high } \\
\text { active choice }\left(\mathrm{ac}_{3}\right)\end{array}$ \\
\hline P303 & $\begin{array}{l}\text { LVQ method to classify the players motivation } \\
\text { behavior of Persistence }(\mathrm{ps}) \text { into low persistence } \\
\left(\mathrm{ps}_{1}\right) \text {, semi-persistence }\left(\mathrm{ps}_{2}\right) \text {, or high persistence } \\
\left(\mathrm{ps}_{3}\right)\end{array}$ \\
\hline P304 & $\begin{array}{l}\text { LVQ method to classify the players motivation } \\
\text { behavior of mental effort (me) into low mental } \\
\text { effort }\left(\mathrm{me}_{1}\right) \text {, semi-mental effort }\left(\mathrm{me}_{2}\right) \text {, or high } \\
\text { mental effort }\left(\mathrm{me}_{3}\right)\end{array}$ \\
\hline P305 & Value is one or zero \\
\hline P306 & Value is one or zero \\
\hline P307 & Value is one or zero \\
\hline P401 & Value is active choice $(\mathrm{ac})$ or zero \\
\hline P402 & Value is persistence $(\mathrm{ps})$ or zero \\
\hline P403 & Value is mental effort (me) or zero \\
\hline P5 & Motivation leveling algorithm \\
\hline P6 & $\begin{array}{l}\text { Responds to the players level of motivation } \\
\text { behavior as the reference to selection of problem } \\
\text { in game }\end{array}$ \\
\hline
\end{tabular}
st, st $=\{\{b, m, c\},\{b, m\}, o, i\}$ is the step of player playing the
TABle 4: Details of place on Motivation Behavior Game Model.

game which contains picking up question, trying to answer, searching info, and overlooking in tests (P212 and T212):

$$
\mathrm{st}=\frac{o+i+q+\operatorname{tr}}{4}
$$

Three domains of MBG are (i) mental effort, (ii) persistence, and (iii) active choice domain. $e \in$ me, st $\in$ me, me $=\{\{b, m, c\},\{\{b, m, c\},\{b, m\}, o, i\}, t, b\}$ is mental effort domain which contains self-efficacy, step, time, and correct items (P304 in Table 4). $e \in$ ps, st $\in$ ps, tr $\in$ ps, $\mathrm{ps}=\{\{b, m, c\},\{\{b, m, c\},\{b, m\}, o, i\},\{b, m\}, t\}$ is persistence 
TABLE 5: Details of transition on Motivation Behavior Game Model.

\begin{tabular}{|c|c|}
\hline Transition & Interpretation \\
\hline T203 & $\begin{array}{l}\text { The result of the frequency of neglected in tests or } \\
\text { avoided in games }\end{array}$ \\
\hline T204 & $\begin{array}{l}\text { The result of how many times the players search } \\
\text { info }\end{array}$ \\
\hline T205 & The result of wrong in tests or losses in games \\
\hline T206 & $\begin{array}{l}\text { The result of the players is uncertainty (cancel)/to } \\
\text { decline (escape) }\end{array}$ \\
\hline T207 & The result of true/win \\
\hline T208 & $\begin{array}{l}\text { The count of how much the players use time to } \\
\text { finish the job }\end{array}$ \\
\hline T209 & $\begin{array}{l}\text { Average of loss }(m) \text {, cancel }(c) \text {, and victory }(b) \\
\text { values }\end{array}$ \\
\hline $\mathrm{T} 210$ & Average of loss $(m)$ and victory $(b)$ values \\
\hline T211 & $\begin{array}{l}\text { Sum of } 30 \% \text { loss }(m), 20 \% \text { cancel }(c) \text {, and } 50 \% \\
\text { victory }(b) \text { values }\end{array}$ \\
\hline $\mathrm{T} 212$ & $\begin{array}{l}\text { Average of avoiding }(o) \text {, searching info }(i) \text {, picking } \\
\text { question }(q) \text {, and trying to answer }(\operatorname{tr}) \text { values }\end{array}$ \\
\hline T301 & $\begin{array}{l}\text { Obtain the highest value of the } m, b, c, q \text {, or } \operatorname{tr} \\
\text { (max. value) }\end{array}$ \\
\hline T301a & Divide the $i$ value by the $\max$ \\
\hline T301b & Divide the $q$ value by the $\max$ \\
\hline T301c & Divide the st value by the $\max$ \\
\hline T301d & Divide the tr value by the $\max$ \\
\hline T301e & Divide the $e$ value by the max \\
\hline T301f & Divide the $b$ value by the max \\
\hline T301g & Divide the $t$ value by the max \\
\hline T302 & $\begin{array}{l}\text { Set one value if then value of high active choice } \\
\left(\mathrm{ac}_{3}\right) \text { in LVQ method is higher than value of high } \\
\text { persistence }\left(\mathrm{ps}_{3}\right) \text { or value of high mental effort } \\
\left(\mathrm{me}_{3}\right) \text {, or else reset (zero value) }\end{array}$ \\
\hline T303 & $\begin{array}{l}\text { Set one value if then value of high persistence }\left(\mathrm{ps}_{3}\right) \\
\text { in LVQ method is higher than value of active } \\
\text { choice }\left(\mathrm{ac}_{3}\right) \text { or value of high mental effort }\left(\mathrm{me}_{3}\right) \text {, } \\
\text { or else reset (zero value) }\end{array}$ \\
\hline T304 & $\begin{array}{l}\text { Set one value if then value of high mental effort } \\
\left(\mathrm{me}_{3}\right) \text { in LVQ method is higher than value of high } \\
\text { persistence }\left(\mathrm{ps}_{3}\right) \text { or value of active choice }\left(\mathrm{ac}_{3}\right) \text {, or } \\
\text { else reset (zero value) }\end{array}$ \\
\hline T401 & To multiply \\
\hline $\mathrm{T} 402$ & To multiply \\
\hline $\mathrm{T} 403$ & To multiply \\
\hline
\end{tabular}

domain which contains self efficacy, step, trying to answer, and time (P303 in Table 4), whereas, $q \in \mathrm{ac}$, st $\in \mathrm{ac}$, ac $=$ $\{\{b, m, c\},\{\{b, m, c\},\{b, m\}, o, i\}, i\}$ is an active choice domain which contains picking up question, step, and searching info (P302 in Table 4). To classify this domain, LVQ method is used (shown in Figure 3).

$L=(s, j)$ is MBG representative (P305, P306, and P307 in Table 4), $s$ is the notation of three domains in MBG, and $j$ is three levels in every domain. $L$ has nine probability outcomes; those are (i) low mental effort, (ii) semimental effort, (iii) high mental effort, (iv) low persistence, (v) semipersistence, (vi)

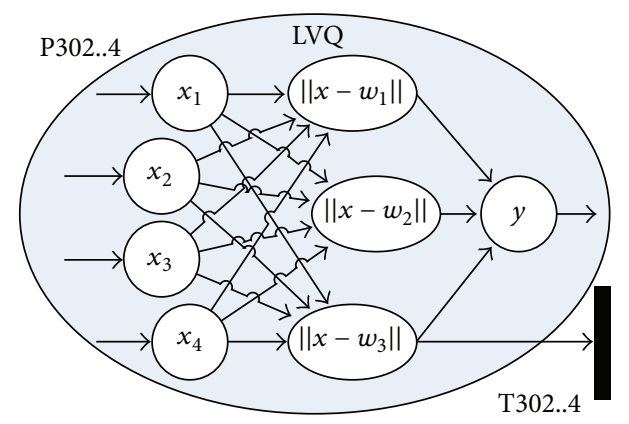

Figure 3: LVQ method in P302, P303, and P304 of Motivation Behavior Game Model.

high persistence, (vii) low persistence, (viii) semipersistence, and (ix) high persistence.

3.3. LVQ Method. Many methods can be used for classifying data. Learning Vector Quantization (LVQ) is the data classification method used in this research. LVQ is supervised Artificial Neural Network (ANN) using competitive learning method developed by Kohonen et al. [25], used in guided training from layers in ANN competition. Competitive layers will automatically learn to improve the classification of input vector performance periodically. When some input has very close distance vectors, those vectors will be grouped into the some class:

$$
c=\arg \min \left\|x-w_{j}\right\| .
$$

The algorithm of an LVQ includes learning and recalling processes. In the learning process, in order to achieve accurate classification, Euclidean distance $\left(D_{i}\right)$ is utilized as a basic rule of competition [26]:

$$
D_{j}=\left\|x-w_{j}\right\|=\sqrt{\sum_{i}\left(x_{i}-w_{i j}\right)^{2}} .
$$

LVQ is used to classify data of input vector in MBG into three clusters. The input vector of LVQ is the weight of variables in MBG, namely, weight of trying to answer, picking up questions, competency, errors, and cancellation. The outcomes of LVQ are three clusters of motivation behavior data type, namely, mental effort (me), persistence (ps), and active choice (ac) motivation behavior with three levels of clusters each. Those levels are high, middle, and low levels:

$$
\begin{aligned}
\mathbf{x}_{1, \mathrm{me}} \Longleftrightarrow t, \quad \mathbf{x}_{2, \mathrm{me}} & \Longleftrightarrow b, \quad \mathbf{x}_{3, \mathrm{me}} \Longleftrightarrow e, \quad \mathbf{x}_{4, \mathrm{me}} \Longleftrightarrow \mathrm{st}, \\
\mathrm{me}_{j} & =\sqrt{\sum_{i}\left(\mathbf{x}_{i, \mathrm{me}}-\mathbf{w}_{i j, \mathrm{me}}\right)^{2}} \\
C_{j, \mathrm{me}} & =\arg \min \left\|\mathbf{x}_{\mathrm{me}}-\mathbf{w}_{j, \mathrm{me}}\right\|
\end{aligned}
$$

$\mathrm{me}_{j}$ is the value of mental effort in MBG (P304 in Table 4), and $C_{j, \mathrm{me}}$ is the classification of mental effort level. Three classes of mental effort are $j=\{1,2,3\}$, in which (i) the 
value of $j$ is equal to one at $j$, me for low condition of mental effort representation index, (ii) semimental effort index will be presented with $j$ having value of two at $j$, me, and (iii) three is the value of $j$ at $j$, me for index of high mental effort conditions. The variables $t, b, e$, and st for mental effort have weight $(\mathbf{w})$. The weight of me in $j$ class is $\mathbf{w}_{j, \mathrm{me}}$.

$\mathrm{ps}_{j}$ is the value of persistence variable in MBG (P303 in Table 4), $C_{j, \mathrm{ps}}$ is the classification of persistence level. Three persistence classes are $j=\{1,2,3\}$ in which (i) $j$ value which is one at $j$, ps is used as a representation index for low persistence, (ii) $j$ which is two at $j$, ps is the index for semipersistence, and (iii) $j$ which is three at $j$, ps is the index for high persistence. The weight of $\mathrm{ps}$ in $j$ class is $\mathbf{w}_{j, \mathrm{ps}}$ :

$$
\mathbf{x}_{1, \mathrm{ps}} \Longleftrightarrow t, \quad \mathbf{x}_{3, \mathrm{ps}} \Longleftrightarrow e, \quad \mathbf{x}_{4, \mathrm{ps}} \Longleftrightarrow \mathrm{st}, \quad \mathbf{x}_{5, \mathrm{ps}} \Longleftrightarrow \mathrm{tr}
$$

$$
\begin{aligned}
\mathrm{ps}_{j} & =\sqrt{\sum_{i}\left(\mathbf{x}_{i, \mathrm{ps}}-\mathbf{w}_{i j, \mathrm{ps}}\right)^{2}}, \\
C_{j, \mathrm{ps}} & =\arg \min \left\|\mathbf{x}_{\mathrm{ps}}-\mathbf{w}_{j, \mathrm{ps}}\right\|,
\end{aligned}
$$

$\mathrm{ac}_{j}$ is the value active choice variable in MBG (P302 in Table 4) in which $C_{j, \text { ac }}$ is the classification of active choice level. Three active choice classes are $j=\{1,2,3\}$ where (i) $j$ which is one at $j$, ac variable means the index for low active choice, (ii) $j$ which is two at $j$, ac is the index for semiactive choice, and (iii) $j$ which is three at $j$, ac is index for high active choice. The weight of ac in $j$ class is $w_{j, \text { ac }}$ :

$$
\begin{gathered}
\mathbf{x}_{4, \mathrm{ac}} \Longleftrightarrow \mathrm{st}, \quad \mathbf{x}_{6, \mathrm{ac}} \Longleftrightarrow q, \quad \mathbf{x}_{7, \mathrm{ac}} \Longleftrightarrow i, \\
\mathrm{ac}_{j}=\sqrt{\sum_{i}\left(\mathbf{x}_{i, \mathrm{ac}}-\mathbf{w}_{i j, \mathrm{ac}}\right)^{2}}, \\
C_{j, \mathrm{ac}}=\arg \min \left\|\mathbf{x}_{\mathrm{ac}}-\mathbf{w}_{j, \mathrm{ac}}\right\| .
\end{gathered}
$$

Some researchers use the optimum method based on LVQ $[12,23] . L$ is the classification of MB optimum conditions. $L$ is defined at three probability optimum conditions, namely, (i) mental effort, (ii) persistence, and (iii) active choice. MB is the classification of MBG outcome that can be defined at nine probability optimum conditions, namely, (i) high mental effort, (ii) semimental effort, (iii) low mental effort, (iv) high persistence, (v) semipersistence, (vi) low persistence, (vii) high active choice, (viii) semiactive choice, and (ix) low active choice:

$$
\begin{gathered}
L=\arg \min \left\|\left\{\mathrm{me}_{3}, \mathrm{ps}_{3}, \mathrm{ac}_{3}\right\}\right\|, \\
\mathrm{MB}= \begin{cases}C_{j, \mathrm{me}}, & \text { if } L=\mathrm{me}_{3} \\
C_{j, \mathrm{ps}}, & \text { if } L=\mathrm{ps}_{3} \\
C_{j, \mathrm{ac}}, & \text { if } L=\mathrm{ac}_{3} .\end{cases}
\end{gathered}
$$

$L$ is considered as mental effort if high mental effort $\left(\mathrm{me}_{3}\right)$ value is smaller than high persistence $\left(\mathrm{ps}_{3}\right)$ and smaller than high active choice $\left(\mathrm{ac}_{3}\right)$ too (T304 in Table 5). Then MB is low mental effort if $C_{j \text {,me }}$ value is close to low mental effort value. $\mathrm{MB}$ is semimental effort if $C_{j, \text { me }}$ value is close to semimental effort value, and then, $\mathrm{MB}$ is high mental effort if $C_{j, \text { me }}$ value is close to high mental effort value.

The description of $L$ is persistence; that is when the value of high persistence $\left(\mathrm{ps}_{3}\right)$ is smaller than high mental effort $\left(\mathrm{me}_{3}\right)$ and smaller than high active choice $\left(\mathrm{ac}_{3}\right)$ too (T303 in Table 5). $\mathrm{MB}$ is low persistence if $C_{j, \mathrm{ps}}$ value is close to low persistence value, $\mathrm{MB}$ is semipersistence if $C_{j, \mathrm{ps}}$ value is close to semipersistence value, and $\mathrm{MB}$ is high persistence if $C_{j, \mathrm{ps}}$ value is close to high persistence value.

$L$ is active choice outcome probabilities which is obtained if the value of high active choice $\left(\mathrm{ac}_{3}\right)$ is smaller than high mental effort $\left(\mathrm{me}_{3}\right)$ and smaller than persistence $\left(\mathrm{ps}_{3}\right)$ too (T302 in Table 5). Then, MB is low active choice if $C_{j, \text { ac }}$ value is close to low active choice value, $\mathrm{MB}$ is semiactive choice if $C_{j, \mathrm{ac}}$ value is close to semiactive choice value, and MB is high active choice if $C_{j, \text { ac }}$ value is close to high active choice value.

\section{Experiment}

We conducted a survey to twenty teachers to obtain three characteristics of motivation behavior. The reason of choosing teachers as the respondents is to get the ideal motivation behavior characteristics based on the assumption that teachers are the best motivation behavior evaluator. Furthermore, the fact that teachers have the qualification as pedagogic assessors which is shown by their diplomas, certificates, and teaching experience is also taken into consideration. Therefore, teachers are reliable in determining the parameters of motivation behavior indicators for their pupils.

The population is senior high school teachers that consist of two groups, twelve respondents are math and science teachers, and eight respondents are social teachers.

Teachers will give weight of the variable reference that can influence the value of type $(L)$ and class $(C)$ of motivation behavior. Variable reference from teachers includes using time $(t)$, correct/victory $(b)$, self-efficacy $(e)$, step report (st), trying to answers (tr), picking questions $(q)$, and searching info $(i)$.

Parameters of motivation behavior characteristic value can be used as a motivation behavior reference. The reference of motivation behavior is the value of ideal motivation behaviors. Values of the parameters in the motivation behavior reference data are obtained from the classification of the teachers' survey data. Data of motivation behavior characteristic from teachers will be applied on learning rate of the LVQ motivation behavior pattern.

Populations of motivation behavior classification in this research are 33 pupils, including 18 males and 15 females. The respondents are students in a senior high school who are 16 to 19 years old. They are used to test the MBG system based on LVQ that will classify the student's motivation.

Values of $t, b, o, c, m$, and $i$ are taken when students play the game. The variables of $t, b, o, c, m$, and $i$ are players' characteristic of motivation behavior. These variables are the input of MBG.

To ensure that MBG is really measuring behavioral motivations of individual player's character, the measurements are repeated. To determine the consistency of the level of 
TABLE 6: Weight of motivation behavior reference.

\begin{tabular}{|c|c|c|c|c|c|c|c|c|}
\hline $\begin{array}{l}\text { Using time } \\
(t)\end{array}$ & $\begin{array}{c}\text { Correct/victory } \\
\text { (b) }\end{array}$ & $\begin{array}{c}\text { Self-efficacy } \\
(e)\end{array}$ & $\begin{array}{l}\text { Step report } \\
\text { (st) }\end{array}$ & $\begin{array}{c}\text { Try to } \\
\text { answers } \\
\text { (tr) }\end{array}$ & $\begin{array}{c}\text { Pick } \\
\text { questions } \\
(q)\end{array}$ & $\begin{array}{l}\text { Search info } \\
\quad(i)\end{array}$ & $\begin{array}{l}\text { Class } \\
(C)\end{array}$ & $\begin{array}{c}\text { Motivation } \\
\text { behavior } \\
\text { type }(L)\end{array}$ \\
\hline 0.860 & 0.159 & 0.150 & 0.369 & - & - & - & Low & \\
\hline 0.141 & 0.869 & 0.820 & 0.900 & - & - & - & Semi & $\begin{array}{l}\text { Mental effort } \\
\text { (me) }\end{array}$ \\
\hline 0.120 & 0.830 & 0.849 & 0.141 & - & - & - & High & \\
\hline 0.100 & - & 0.860 & 0.498 & 0.900 & - & - & Low & \\
\hline 0.810 & - & 0.100 & 0.900 & 0.129 & - & - & Semi & Persistence (ps) \\
\hline 0.900 & - & 0.130 & 0.100 & 0.100 & - & - & High & \\
\hline- & - & - & 0.120 & - & 0.498 & 0.498 & Low & \\
\hline- & - & - & 0.820 & - & 0.100 & 0.139 & Semi & Active choice (ac) \\
\hline - & - & - & 0.873 & - & 0.879 & 0.869 & High & \\
\hline
\end{tabular}

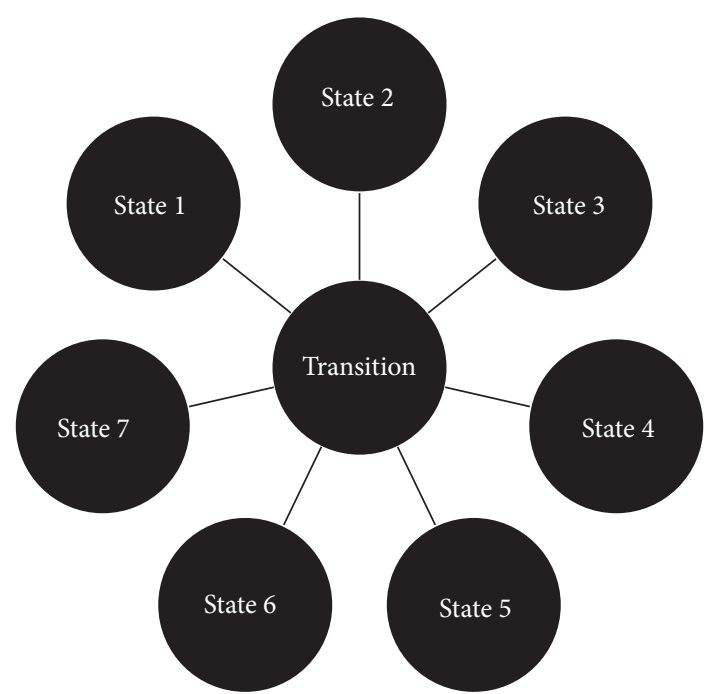

Figure 4: Scenario of Motivation Behavior Game Model.

motivation for the players repeated measurements up to 7 times with 7 different states, players must complete different task types at each state. In this game, the level of difficulty and the environment are made in the same conditions.

Scenario game at MBG is shown in Figure 4. Players must complete the tasks within each state. After completing the task the player will return to later transition into another state. Game is complete if the player has completed the task of all existing states.

From Scenario of Motivation Behavior Game in Figure 4, screen shoot transition place at MBG is shown in Figure 5. Players must be go in this place to choice the state. Players who had entered into a certain space (state) cannot do it again. Player is directed to take the new state.

Screen shoot one of state place at MBG is shown in Figure 6. Of the transition location, players will be entered into one of the existing state spaces (one of seven states). Players must complete the tasks in each state. Players cannot leave the room before completing the task, at least $75 \%$ of all available tasks. This is done for players to master learning.

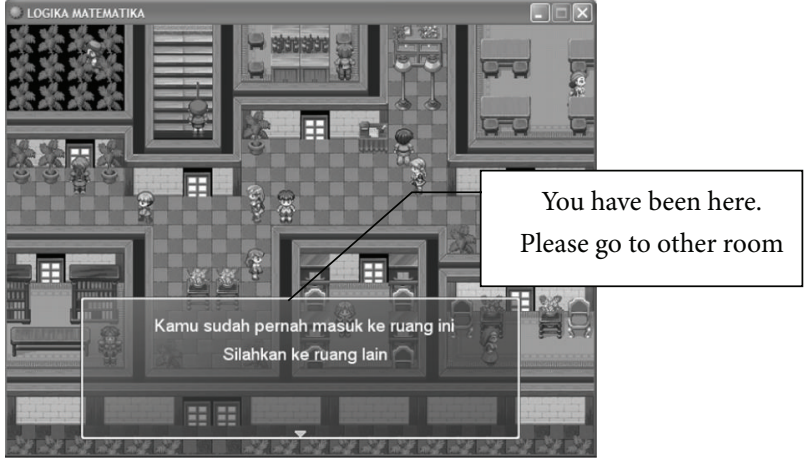

FIGURE 5: Screen shoot of transition place.

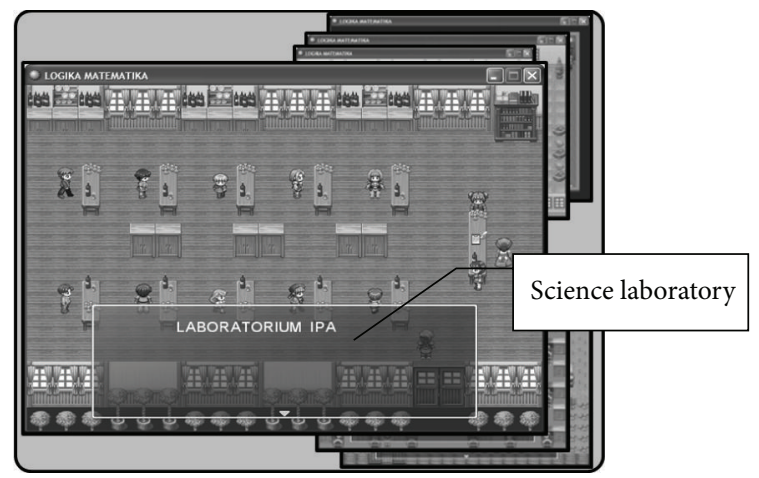

FIGURE 6: Screen shoot of state place.

\section{Result}

5.1. Value of Motivation Behaviors. MBG is embedded in sensitivity of teachers in the game. It is because MBG data training is taken from the teachers. The data observation from the teacher is ideal data that can be used as training data in LVQ method. LVQ training outcome is used as weight value reference of motivation behavior classification. Table 6 is the result of LVQ training (from data teachers) which includes weight of using time $(t)$, weight of correct/victory $(b)$, weight of self-efficacy $(e)$, weight of step report (st), weight of trying 
TABle 7: Results of experiments in State 7.

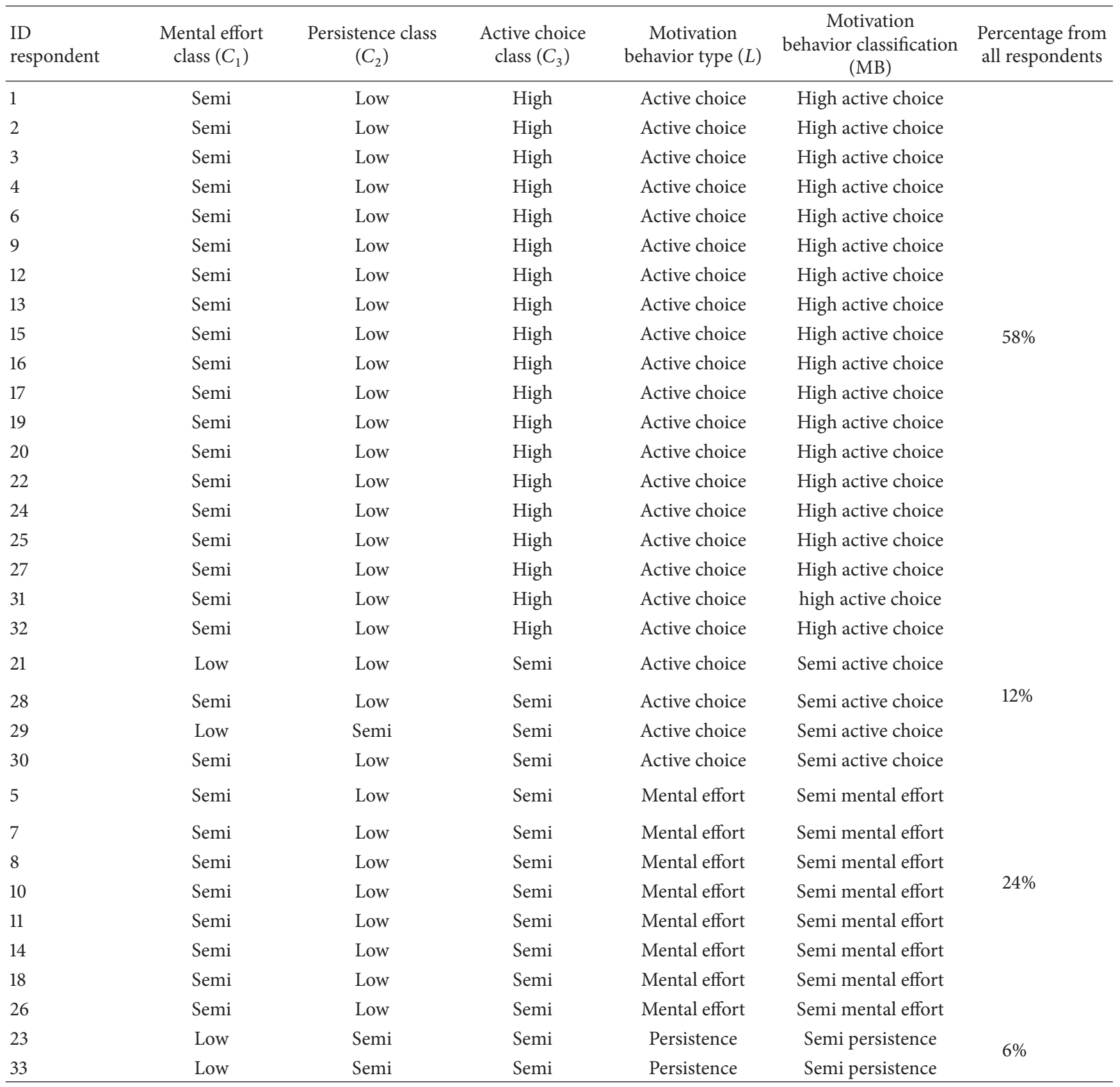

to answers (tr), weight of picking questions $(q)$, and weight of searching info $(i)$. The value of Table 6 is a reference weight value of motivation behavior in the MBG. The table value shows the character of motivation behavior reference which is in accordance with the players' character.

5.2. Motivation Behavior Classification. From (7), (9), (11), and (12), it can be stated that this research is a method implementation in game to know the three motivation behaviors from 33 players (students) and three motivation levels in each motivation behavior.

Table 7 shows the result of experiment in State 7. Fiftyeight percent players have high active choice motivation behavior. Twelve percent have semiactive choice motivation behavior; twenty-four percent have semimental effort, while six percent have semipersistence motivation behavior.

Table 8 shows the number of players at each state (State 1 to State 7) which is classified into six motivation behaviors, namely, high mental effort, semimental effort, low mental effort, high persistence, semipersistence, low persistence, high active choice, semiactive choice, and low active choice. In the mental effort classification, players tend to be dominantly at the semimental effort. Players on the persistence motivation behavior are dominant on low persistence, whereas high active choice for players tends to have active choice motivation type. 
TABLE 8: The number of players based on motivation behavior at each state.

\begin{tabular}{|c|c|c|c|c|c|c|c|c|}
\hline \multirow{2}{*}{\multicolumn{2}{|c|}{ Motivation behavior }} & \multicolumn{7}{|c|}{ State } \\
\hline & & 1 & 2 & 3 & 4 & 5 & 6 & 7 \\
\hline \multirow{3}{*}{ Mental effort } & Low & 0 & 0 & 1 & 4 & 1 & 3 & 4 \\
\hline & Semi & 29 & 32 & 29 & 28 & 32 & 30 & 29 \\
\hline & High & 4 & 1 & 3 & 1 & 0 & 0 & 0 \\
\hline \multirow{3}{*}{ Persistence } & Low & 29 & 31 & 28 & 22 & 31 & 25 & 30 \\
\hline & Semi & 4 & 2 & 5 & 9 & 2 & 8 & 3 \\
\hline & High & 0 & 0 & 0 & 2 & 0 & 0 & 0 \\
\hline \multirow{3}{*}{ Active choice } & Low & 6 & 17 & 17 & 0 & 0 & 0 & 0 \\
\hline & Semi & 3 & 0 & 2 & 18 & 15 & 19 & 14 \\
\hline & High & 24 & 16 & 14 & 15 & 18 & 14 & 19 \\
\hline
\end{tabular}

\section{Discussion}

Some advantages of MBG compared to previous studies on measuring motivation is it does not require additional instruments besides the game being played like in the methods applied by Derbali and Frasson [17]. It is due to the fact that MBG is assessments embedded in immersive games to reveal the behavior of player's motivation. MBG as an indirect measurement of motivation levels avoids bias measurement due to a self-reported enjoyment done by Bernard and Cannon [15] in their research. This indirect measurement of players' motivation characteristics is done by observing the players' motivation behavior. MBG is model assessments of intrinsic and extrinsic motivation as described by Konetes [16].

6.1. Analysis of Motivation Behavior Characteristic. The characteristic of motivation behavior is divided into three objective groups, namely, mental effort, persistence, and active choice motivation behavior. Mental effort motivation behavior is the first objective motivation performance of the players during the process of completing a game mission; the players with mental effort motivation have the characteristics as follows: being always confident with high level of efficiency to using time, never making mistakes, having a high competence (high self-efficacy), and being effective to finish the tasks thoroughly.

Persistence motivation behavior is the second objective motivation performance at the time of completing the mission of the game. Persistence has objective characteristics including; tendency to low self-efficacy, low efficiency in using time, few trials to answer, and finish the tasks thoroughly.

Active choice is the third objective performance of the players' motivation during serious games. The characteristic of active choice including tendency to search information, always respond to get the questions, and low efficiency in solving the problem thoroughly.

6.2. Motivation Behavior Game Multiple Objective. The result of experiment is shown in Table 7. MBG is identified from the motivation behavior of 33 respondents.
MBG represents the three motivation behavior references; those are mental effort, persistence, and active choice motivation behavior references. This is the MBG multiobjective. Player's performance will be strong in one motivation behavior reference and weak in the other. The first objective is mental effort (C1), the second objective is persistence (C2), and the third objective is active choice (C3). Table 7 shows, how the 33 respondents are having the nature of multi objective of each type of motivation behavior.

6.3. Validation of Measurement. Figure 7 shows two examples of the level of player's consistency; Figure 7(a) is the consistent result of the player's motivation level; while Figure 7(b) is the opposite, the results of player's motivation level are not consistent.

Level of motivation shown by notation of numbers: level 1 is the low motivation, level 2 is the middle motivation (semi), and level 3 is the high motivation. The consistency is measured by the changes of players motivation level at each game stage (stage 1 to stage 7 ). The lower deviation of motivation level among stages is the higher the validity of the measurements is; otherwise the higher deviation of motivation level among stages, the lower the validity of the measurement. Figure $7(\mathrm{a})$ is an example of the level of minimum deviation $(0 \%)$, which is a characteristic of a valid measurement, because the measurement of the level of motivation of a player generates a consistent value on the same level although for different tasks. And Figure 7(b) is an example of the level of maximum deviation (100\%); this is a characteristic of an invalid measurement, because the measurement of the level of motivation of a player generates inconsistent values on the same level on each task. Deviation of player motivation level is determined by using (13)

$$
D_{p}=\sum_{s}\left(x_{s}-\bar{x}_{s p}\right)^{2} \text {. }
$$

The measurements results of the player's mental effort level are shown in Figure 8. The activity of each player in resolving the seven states is depicted on horizontal lines, the level of players motivation represented by line position at level 1,2 , and 3 . Level 1 is the lowest level of low mental effort, level 2 is middle level called semimental effort, and level 3 is the highest level of motivation called high mental effort. Figure 8 shows the tendency of players' dominant motivation consistency at the semimental effort.

The measurement results of persistence levels shown in Figure 9: level 1 is the lowest level called low persistence, level 2 is middle level called semipersistence, and level 3 is the highest level called high persistence. Figure 9 shows the tendency of players' dominant motivation consistency on the level of low persistence.

The measurement results of active choice levels shown in Figure 10: level 1 is the lowest level called low active choice, level 2 is middle level called semiactive choice, and level 3 is the highest level called high active choice. Figure 10 shows the tendency of few players' dominant motivation consistency on the level of high active choice.

Table 9 shows the percentage of the number of players based on the deviation levels of motivation. Deviation level 


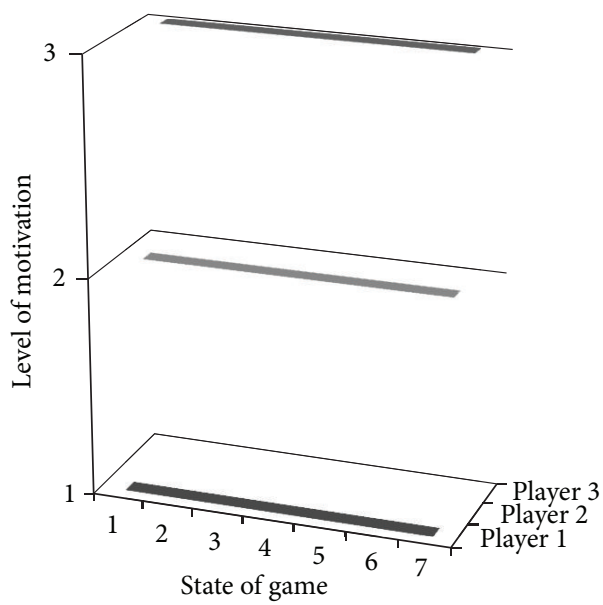

(a)

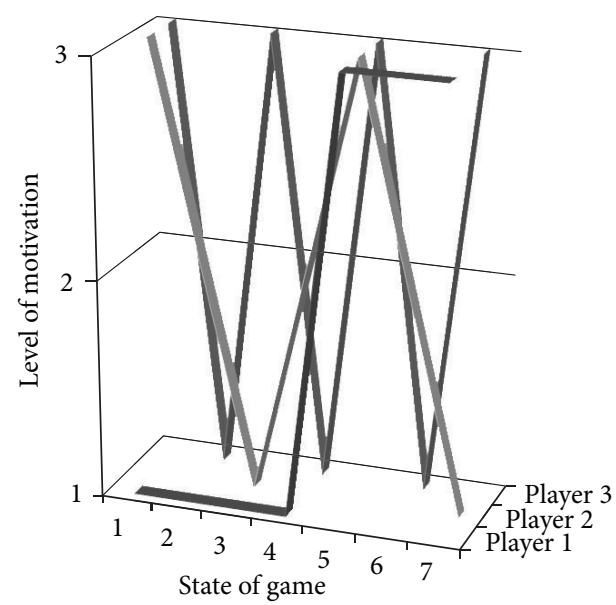

(b)

FIgURE 7: The consistency level of player's motivation (a): the example of deviation rate of $0 \%$ (minimum deviation); as the characteristic measurement results are valid, the players are consistent with the level of motivation (b): the example of deviation rate of $100 \%$ (maximum deviation); as the characteristic measurement results are invalid, the players are not consistent with the level of motivation.

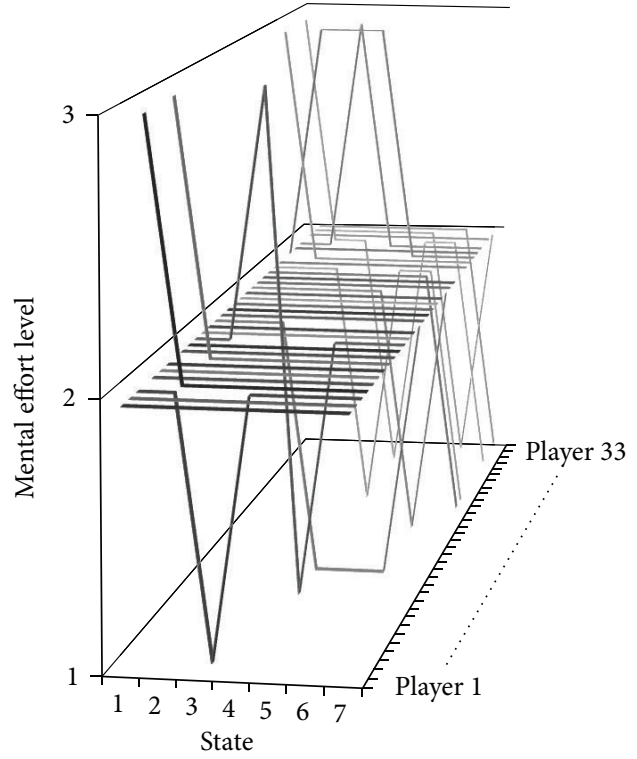

FIgURE 8: Level of players' mental effort in State 1 to State 7.

column is the division of the three levels of motivation deviation on each task, namely, none $(0 \%), \leq 25 \%$, and $\leq 50 \%$ deviation. The percentage shown in Table 9 is the percentage of the number of players from the entire cast (33 students). As described in Figure 1, the measurement is considered invalid if the measurement repeated times will produce the same value (none deviation). By contrast, measurements are declared invalid if the measurement done several times produces a very high deviation (maximum deviation). These deviation values are expressed in percentage $0 \%$ (none deviation) up to $100 \%$ (maximum deviation).

Table 9 shows the number of players is consistent in the motivation level, which is characterized by low values of the deviation rate, so that measurements of motivation by

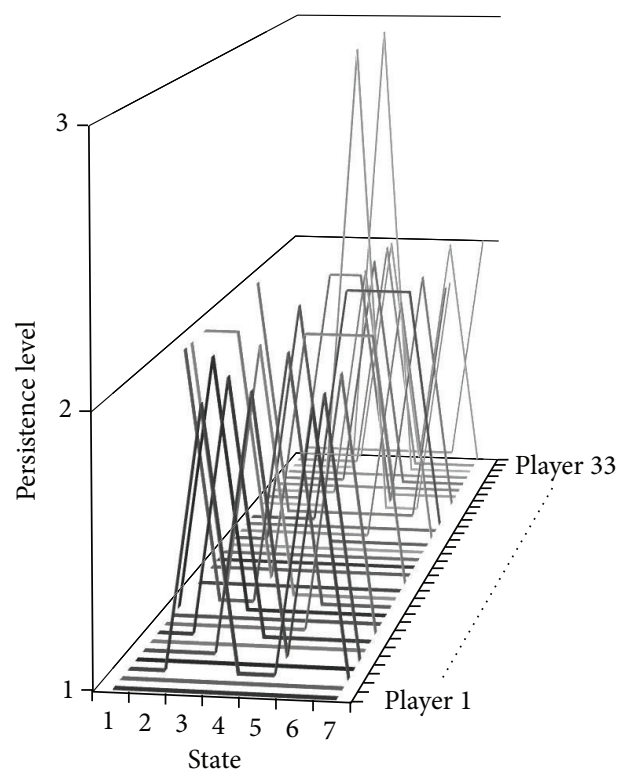

FIGURE 9: Level of players' persistence in State 1 to State 7.

TABLE 9: The number of players based on deviation level.

\begin{tabular}{lccc}
\hline $\begin{array}{l}\text { Motivation } \\
\text { behavior }\end{array}$ & Deviation level & $\begin{array}{c}\text { Number of } \\
\text { players }\end{array}$ & $\begin{array}{c}\text { Percentage } \\
\text { of all players }\end{array}$ \\
\hline \multirow{3}{*}{ Mental effort } & None & 19 & $58 \%$ \\
& $\leq 25 \%$ & 31 & $94 \%$ \\
Persistence & $\leq 50 \%$ & 33 & $100 \%$ \\
& none & 13 & $39 \%$ \\
Active choice & $\leq 25 \%$ & 31 & $94 \%$ \\
& $\leq 50 \%$ & 32 & $97 \%$ \\
& None & 8 & $24 \%$ \\
& $\leq 25 \%$ & 19 & $58 \%$ \\
\hline
\end{tabular}




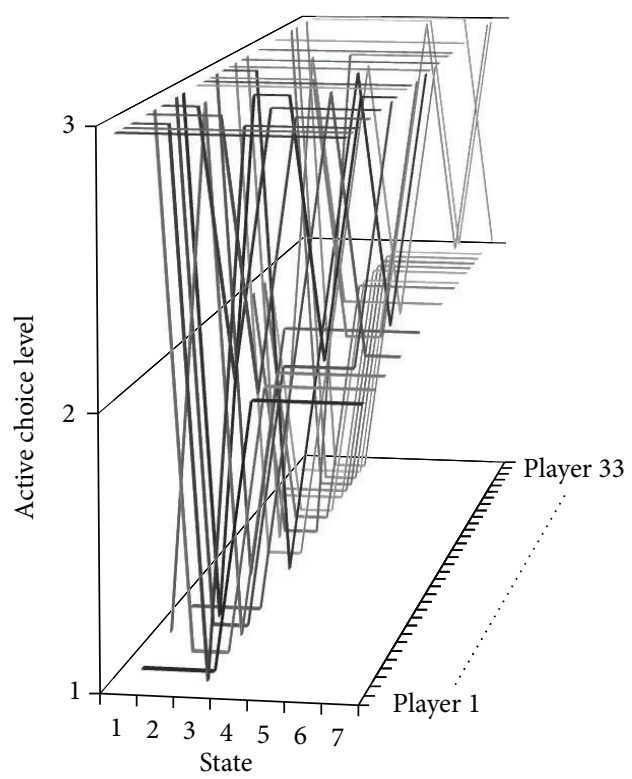

Figure 10: Level of players' active choice in State 1 to State 7.

MBG can be said to be valid. More than $50 \%$ of players have a deviation of less than or equal to $25 \%$. Even for mental effort and persistence over $90 \%$ of players have a motivation deviation of less than or equal to $25 \%$.

\section{Conclusion}

In MBG modeling research, the model of MBG with Petri net and function of motivation behavior identification can be gotten. LVQ method is used to classify player's characteristic in playing games.

In MBG classification research, the game can identify the players' motivation behavior. Players can be classified into three motivation behavior clusters namely, (i) mental effort, (ii) persistence, and (iii) active choice; the percentage of each classification is $24 \%$ semimental effort, $6 \%$ semipersistence, $58 \%$ high active choice, and $12 \%$ semiactive choice.

In a further research, it is hoped that MBG can provide feedback to determine the level or be used as a guide in game. Individual behavior can influence the scenario changes in game. MBG can be fun and vary based on the personality challenges in serious games.

To wrap up, it can be concluded that the MBG is embedded assessments of motivation behavior with the sensitivity of teachers in the serious game. MBG disposed has strong multiobjective character of motivation behavior classification. Thus, there is a need of the optimum method based on LVQ. Indirectly, MBG always observes the fluctuation in the interest of the players. MBG informs an accurate level of motivation behavior; it strongly supports the completeness learning in serious game.

\section{References}

[1] T. Marsh, W. L. Wong, E. Carriazo et al., "User experiences and lessons learned from developing and implementing an immersive game for the science classroom," in Proceedings of HCI International 2005, Las Vegas, Nev, USA, July 2005.

[2] D. Clark, "Game and e-learning," Sunderland: caspian learning, April 2009, http://www.caspianlearning.co.uk.

[3] H. Ndahi, "The use of innovative methods to deliver technology education laboratory courses via distance learning: a strategy to increase enrollment," Journal of Technology Education, vol. 17, no. 2, pp. 33-42, 2006.

[4] A. Hayashi, C. C. Chen, and H. Terase, "Aligning IT skills training with online asynchronous learning multimedia technologies," Information Systems Education Journal, vol. 3, no. 26, pp. 3-10, 2005.

[5] N. P. Ololube, "Appraising the relationship between ICT usage and integration and the standard of teacher education programs in a developing economy," International Journal of Education and Development Using Information and Communication Technology, vol. 2, no. 3, pp. 70-85, 2006.

[6] H. C. Arnseth, "Learning to play or playing to learn-a critical account of the models of communication informing educational research on computer gameplay," The International Journal of Computer Game Research, vol. 6, no. 1, 2006.

[7] J. H. Smith, "The games economists play-implications of economic game theory for the study of computer games," The International Journal of Computer Game Research, vol. 6, no. 1, 2006.

[8] R. E. Clark, "Evaluating the learning and motivation effects of serious games," Rosier school of Education Center for Creative Technologies, Augustus 2010, http://projects.ict.usc.edu/itgs/ talks/ Clark_Serious Games Evaluation.ppt.

[9] R. E. Mayer, "Should there be a three-strikes rule against pure discovery learning? the case for guided methods of instruction," American Psychologist, vol. 59, no. 1, pp. 14-19, 2004.

[10] P. A. Kirschner, J. Sweller, and R. E. Clark, "Why minimal guidance during instruction does not work: an analysis of the failure of constructivist, discovery, problem-based, experiential, and inquiry-based teaching," Educational Psychologist, vol. 41, no. 2, pp. 75-86, 2006.

[11] R. E. Clark and S. Choi, "Five design principles for experiments on the effects of animated pedagogical agents," Journal of Educational Computing Research, vol. 32, no. 3, pp. 209-225, 2005.

[12] Y. Inal and K. Cagiltay, "Flow experiences of children in an interactive social game environment," British Journal of Educational Technology, vol. 38, no. 3, pp. 455-464, 2007.

[13] J. Clempner, "Modeling shortest path games with Petri nets: a Lyapunov based theory," International Journal of Applied Mathematics and Computer Science, vol. 16, no. 3, pp. 387-397, 2006.

[14] M. Araújo and L. Roque, “Modeling games with petri nets," Digital Games Research Association (DiGRA) 2009, http://www .digra.org/dl/db/09287.37256.pdf.

[15] R. R. S. Bernard and H. M. Cannon, "Exploring motivation: using emoticons to map student motivation in a business game exercise," Developments in Business Simulation and Experiential Learning, vol. 38, pp. 229-240, 2011.

[16] G. D. Konetes, "The function of intrinsic and extrinsic motivation in educational virtual games and simulations," Journal of Emerging Technologies in Web Intelligence, vol. 2, no. 1, pp. 2326, 2010.

[17] L. Derbali and C. Frasson, "Players' motivation and EEG waves patterns in a serious game environment," Intelligent Tutoring Systems, vol. 6095, no. 2, pp. 297-299, 2010. 
[18] M. A. Syufagi, M. Hariadi, and M. H. Purnomo, "Model of mental effort assessment in pedagogic games based On LVQ method," in Proceedings of SESINDO2008 Conference, pp. 556564, ITS, Surabaya, Indonesia, December 2008.

[19] M. A. Syufagi, M. Hariadi, and M. H. Purnomo, "A cognitive skill classification based on multi objective optimization using learning vector quantization for serious games," ITB Journal of Information and Communication Technology, vol. 5, no. 3, pp. 189-206, 2011.

[20] S. M. Harini, Classification of comprehensive learning achievement effectivity in senior high school students based on mathematical logic game using LVQ Method [M.S. thesis of Electrical Engineering], Institut Teknologi Sepuluh Nopember (ITS), Surabaya, Indonesia, 2009.

[21] M. Abramson and H. Wechsler, "A distributed reinforcement learning approach to pattern inference in go," CiteSeerx, 2011, http://citeseerx.ist.psu.edu/viewdoc/summary?doi= 10.1.1.9.7035.

[22] C. Brom, V. Šisler, and T. Holan, "Story manager in 'Europe 2045' uses petri nets," in Proceedings of the International Conference on Virtual Storytelling (ICVS '07), vol. 4871 of Lecture Notes in Computer Science, pp. 38-50, Strasbourg, France, 2007.

[23] T. Murata, "Petri nets: properties, analysis and applications," Proceedings of the IEEE, vol. 77, no. 4, pp. 541-580, 1989.

[24] D. L. Rahakbauw and Subiono, "An implementation of petri net Hybrid synthesis in manufacture system," 2011, http://digilib.its.ac.id/public/ITS-Master-13439-Paper.pdf.

[25] T. Kohonen, J. Hynninen, J. Kangas, J. Laaksonen, and K. Torkkola, "LVQ_PAK—-the learning vector quantization program package version 3.1, 'Rakentajanaukio 2 C, SF-02150 Espoo Finland, 1995.

[26] C.-R. Che, L.-T. Tsai, and C.-C. Yang, "A neural network approach for random samples to stratified psychometrical population," in Proceedings of the WSEAS International Conference on Sociology, Psychology, Philosophy, pp. 51-54, Penang, Malaysia, March 2010. 

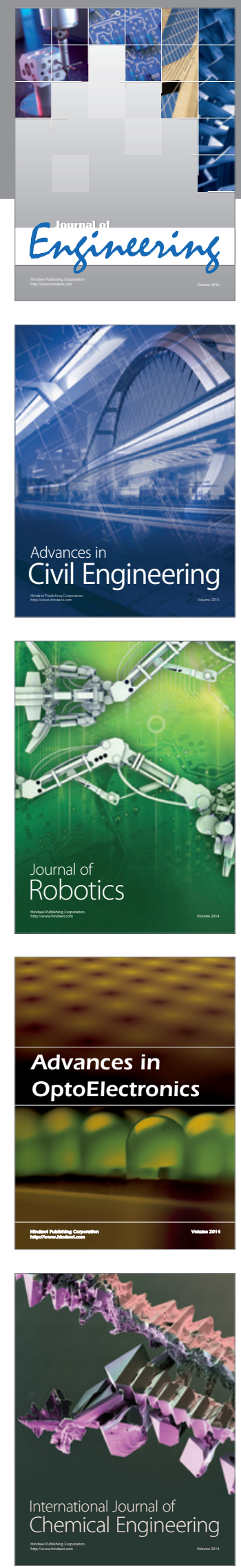

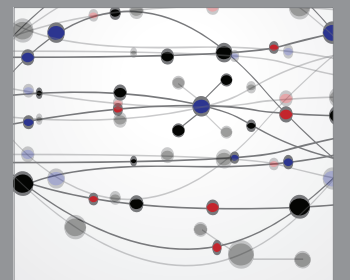

The Scientific World Journal
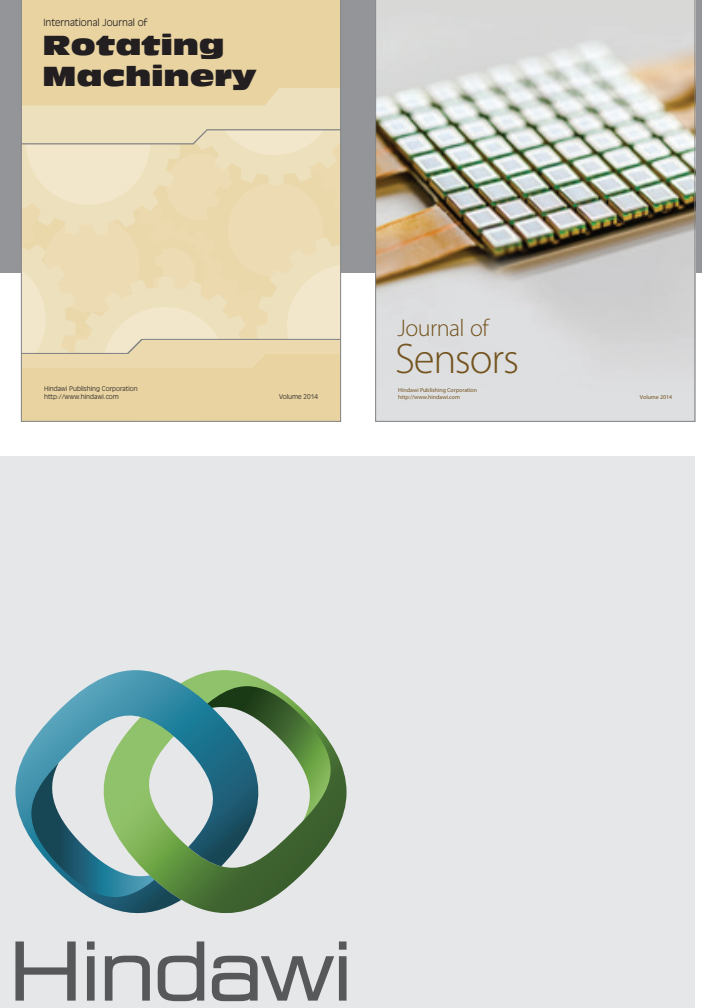

Submit your manuscripts at http://www.hindawi.com
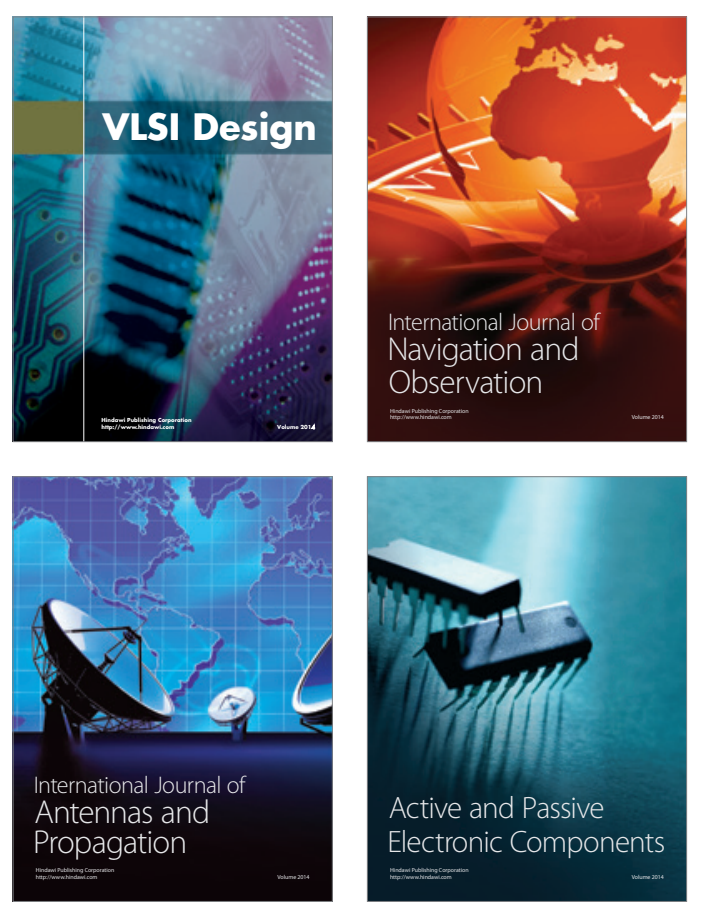
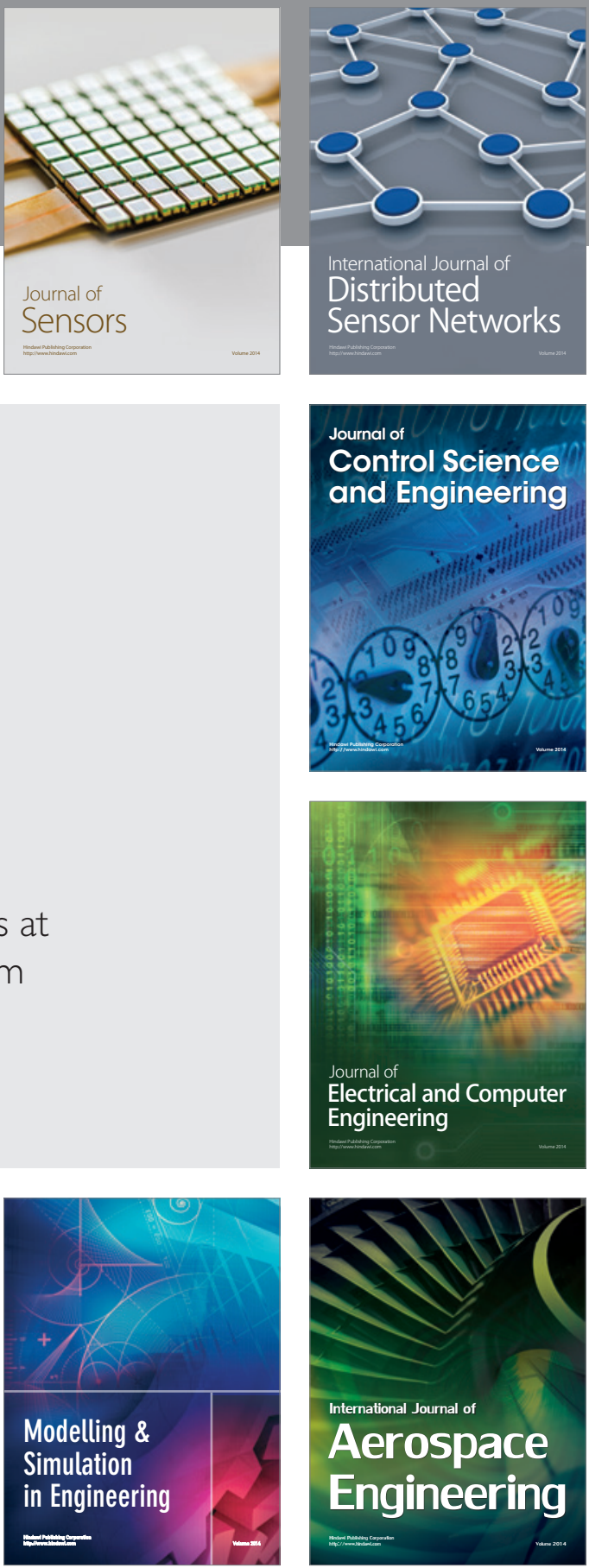

Journal of

Control Science

and Engineering
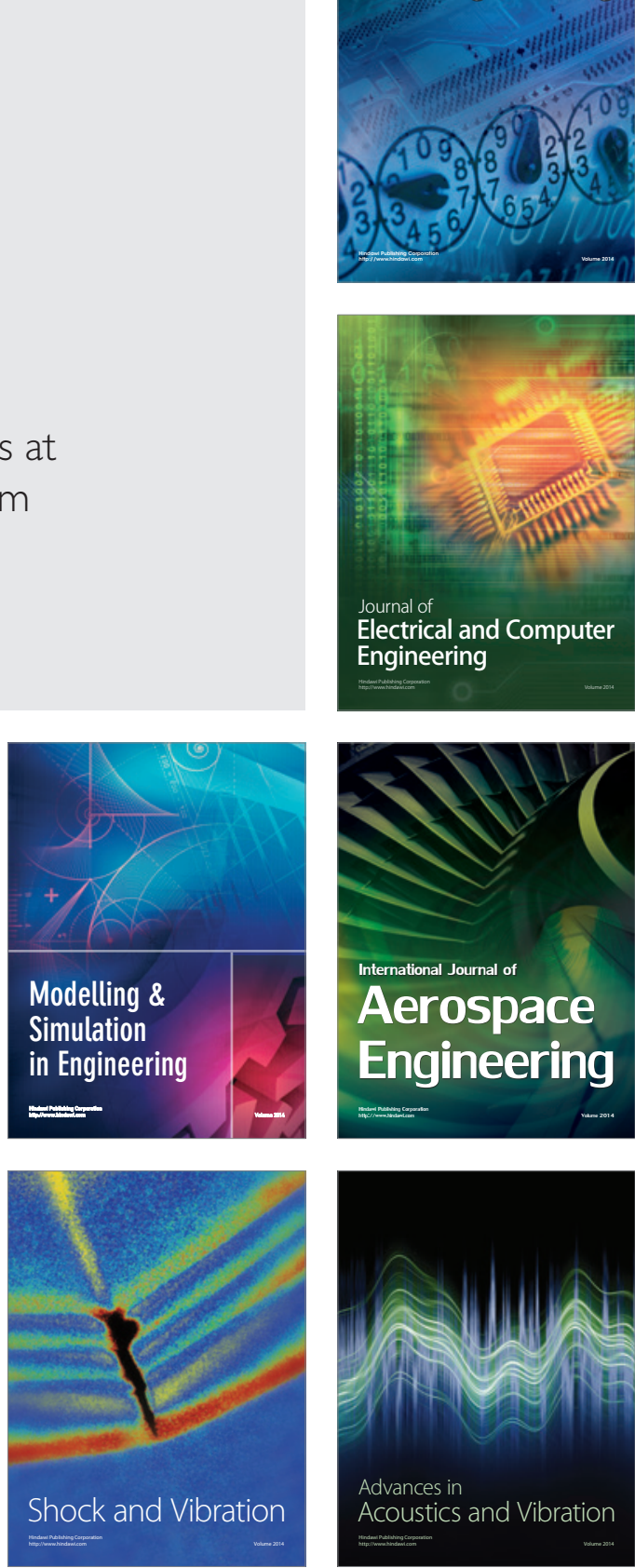